\title{
Development of Information Search Expertise: Research Students' Knowledge on databases
}

Samuel Kai-Wah Chu and Nancy Law

\section{The Authors}

Samuel Kai-Wah Chu* is an Assistant Professor and Nancy Law is an Associate Professor, both in the Division of Information \& Technology Studies, Faculty of Education, the University of Hong Kong, Pokfulam, Hong Kong

\begin{abstract}
Purpose - This paper reports on a study of twelve postgraduate research students' development of information search expertise. It focuses on students' perceived importance and growth of knowledge of different databases as they progress through their studies.

Design/methodology/approach - Taking an in-depth longitudinal approach, this study makes use of surveys, direct observations of students' searching of various databases, students' verbalization of their thoughts while searching databases and interviews during a one-year period. The paper focuses on analyzing the data from surveying and interviewing the students with regard to their use of databases.

Findings - It was found that many students were initially unfamiliar with many of the databases important to them and that the familiarity developed during the year contributed importantly to their development of information search expertise.

Originality/value - The findings suggest that much work has to be done to inform and instruct students about these "treasures". This paper further identifies features that may increase the usefulness of a journal database and makes suggestions on ways to improve library support for the effective use of databases.
\end{abstract}

Keywords Databases, Development, Expertise, Information searches, Knowledge, Postgraduates

Paper type Research paper

\section{Introduction}

Research students, in particular Doctor of Philosophy $(\mathrm{PhD})$ students who are the focus of this research, must select an original research topic and be comprehensive and current in their literature reviews in areas of knowledge related to that research. They must conduct rigorous database searches to support their studies. However, they are often unfamiliar with the various types of sources, databases, or search methods. These students are ideal subjects for information search studies which attempt to understand the growth and development of information search expertise. Relatively few longitudinal studies on expertise development have been conducted which examine the information search behavior of students (Barry, 1997; Libutti and Kopala, 1995; Morner, 1993).

\footnotetext{
* Correspondence to: Sam Chu, Division of Information \& Technology Studies, Faculty of Education, the University of Hong Kong, Pokfulam, Hong Kong.

E-mail address: lbsam@ust.hk
} 
This paper focuses on answering three research questions. First, it attempts to identify the information needs (in terms of databases) of education and engineering research students and investigates whether these needs change over time. Second, it examines whether students' perceived importance of a database will change with the increase in the students' familiarity with the database, and, third, it compares the similarities and differences between the two groups of students in terms of their information search needs.

Understanding students' need for various databases is one of the approaches in examining students' growth in information search expertise. The need for various databases can be measured indirectly by the perceived importance of the databases. This study examined students in two disciplines. A comparison of the changes in knowledge of the databases by the two groups will shed light on whether these changes are dependent on the subject disciplines of the research students.

\section{Literature review}

Past research has shown that students' information search skills are initially inadequate (Bates, 1977; Chu, 1995; Drabenstott \& Weller, 1996; Hildreth, 1997; Tillotson, 1995) even at the PhD level (Barry, 1997; Compton, 1989; Morner, 1993; Simon, 1995; Zaporozhetz, 1987). The logical question then becomes: "what would be a good way to help students acquire the information search knowledge and skills they need to find the desired and necessary information?"

Over the past four decades, many studies have examined the differences between experts and novices in different domains. This body of research is commonly called expertise or noviceexpert research. A good understanding of how people become experts may help the novice shorten his or her learning curve in becoming an expert (Larkin, McDermott, Simon, \& Simon, 1980). Two major approaches to expertise research were noted in the literature: (1), novice-expert comparison, and, (2), developmental studies of expertise. Most research took the novice-expert approach (Ahmed, McKnight, \& Oppenheim, 2004; Chase \& Simon, 1973; Chi, Glaser, \& Farr, 1988; De Groot, 1965, 1966; Hsieh-Yee, 1993; Kuhlthau, 1999; Lazonder, Biemans, \& Wopereis, 2000; Marchionini, Dwiggins, Katz, \& Lin, 1993; Marchionini, Meadow, Dwiggins, Lin, Wang, \& Yuan, 1991; Palmquist \& Kim, 2000); there were a few which took the developmental approach (Campbell, Brown, \& DiBello, 1992; Campbell \& Dibello, 1996; Dreyfus \& Dreyfus, 1980, 1986; Walton, Adams, Goldsmith, \& Feldman, 1988; Wiedenbeck \& Scholtz, 1996).

The novice-expert research has contributed to componential accounts of expertise which have helped to uncover the general characteristics of experts. It has been noted that "experts have a large body of organized knowledge in their own domain of expertise” (Chase \& Simon, 1973; Marchionini, et al., 1993). This knowledge, however, is not sufficient in helping students to 
advance from a novice to an expert. The componential explanation of attaining expertise is, by itself, insufficient to reveal complexities or irregularities in the process of expertise development and, thus, developmental methodologies are also necessary.

None of the developmental studies mentioned above touched on information search expertise. This research adopted a developmental, longitudinal approach to investigate if there are different stages of expertise in information search for research students, and examined what contributes to a novice student's progress from one stage of information search expertise to the next. Two major types of information search expertise are identified in the literature: (1) knowledge of source types/databases, and (2) knowledge of search skills. The first can be broken down further into source types and databases. This paper focuses on the development of students' knowledge of databases.

Past research has examined six major aspects dealing with databases used by academic researchers: (1) whether these users were aware of the databases (Clark \& Gomez, 1990; Weingart \& Anderson, 2000); (2) what databases they used (Clark \& Gomez, 1990; Keller, 2002; Talja \& Maula, 2003; Tefera, Wood \& Ford, 1999); (3) how often various databases were used (Bar-Ilan, Peritz \& Wolman, 2003; Cole, 1992; Majid and Tan, 2002; Simon, 1995; Tefera, Wood \& Ford, 1999); (4) their perceived importance on databases (Bar-Ilan, Peritz \& Wolman, 2003; Weingart \& Anderson, 2000); (5) their knowledge on various databases (Morner, 1993); and (6) whether the databases were easy to use (Ahmed, McKnight \& Oppenheim, 2004; Weingart \& Anderson, 2000). The first four aspects are related to one another and can be summarized into a single aspect: researchers' perceptions of the importance of the sources. Obviously, if researchers think certain resources are important, they will use them extensively.

In assessing the relative importance researchers place on different databases, past research identified the following databases important to (or used frequently by) researchers: Current Contents, Dissertation Abstracts, EBSCOhost, ERIC, INSPEC, Medline, ScienceDirect, and Web of Science (Bar-Ilan, Peritz \& Wolman, 2003; Clark \& Gomez, 1990; Talja \& Maula, 2003; Weingart \& Anderson, 2000).

With regards to students' knowledge of databases, Morner (1993) tested the library research skills (including databases) of 149 education doctoral students using a survey of 41 questions. It was found that, on average, students only answered approximately $50 \%$ of the questions correctly. For example, 28 percents of the students incorrectly answered the question "Which of the following can be used to locate books at other libraries?" The correct answer was OCLC (On-line Computer Library Center), but quite a few chose incorrect answers such as Education Index and Social Science Citation Index. 
One common drawback in some of these previous studies (Bar-Ilan, Peritz, \& Wolman, 2003; Weingart \& Anderson, 2000) is that they did not analyze their data by discipline. For example, Weingart \& Anderson (2000) found that $34.6 \%$ and $65.6 \%$ of all respondents were unaware of ERIC and Compendex Engineering Index respectively. However, it would be more meaningful to find out how many of the education faculty respondents were unaware of ERIC and how many of the engineering faculty respondents were unaware of the Compendex Engineering Index since these are the premier database for the two fields. It is not surprising if many noneducation students were not aware of ERIC. However, it would be alarming if many of the education students were unaware of the education database. There has been little research done investigating students' use of databases over time. In Rogers' (2001) three-year longitudinal survey on the faculty and graduate students' usage of electronic journals at Ohio State University, a small part of the study was conducted on database usage. The study found that faculty consistently used databases more frequently than graduate students.

\section{Research Methods}

This study employed both quantitative and qualitative methods of data collection. Taking a longitudinal approach, this study sought an in-depth understanding of the process where research students move from being novices in information search to becoming expert searchers. It observes the growth and development of the search capabilities of research students in five research meetings conducted over a period of one year. It used the quantitative method to survey the students three times during the research period, and it gathered data qualitatively through observing students' information search with different databases, audio-taping the students' verbalization of their thoughts while searching databases, and interviews. This paper focuses on reporting data from surveying and interviewing the students with regard to their use of databases though data from direct observation and the think-aloud protocol are also used.

This research examines students in two disparate disciplines, engineering and education, to investigate the effects of subject discipline on the students' choice of databases and the development of their information search expertise. Because the study adopted an in-depth longitudinal methodology, only twelve research students (six each from education and engineering) from the University of Hong Kong (HKU) were invited to take part in the study. Preference was given to beginning $\mathrm{PhD}$ students, because they represented the group of students who would conduct the most literature searches in terms of both quantity and depth. Ten of the students were $\mathrm{PhD}$ students (five each from the disciplines of education and engineering) and two were Master of Philosophy (MPhil) students (one from each of the above disciplines). 
Of the twelve students participating in the study, eleven were in the first year of their graduate program when they first joined the study and one was in her third year. This third year student was also a suitable participant since she indicated that she still needed to find substantially more information for her thesis. To minimize the gender effect, there were three male and three female participants from each of the two disciplines. With a small purposive sample of twelve students, the analysis aimed to establish qualitative differences in order to deepen understanding, rather than to establish generalizations. The use of statistical tests was adopted in this study as a means to help identify points of interest for further exploration.

Similar to Yuan's $(1995,1997)$ longitudinal studies on end-users' information search behavior, the data collection for this study was accomplished over a period of one year. To identify students' familiarity with (and their perceived importance of) various databases, a questionnaire on various databases was used. The questionnaire listed the databases in two separate groups: (1) nine that are common to both education and engineering disciplines; (2) a separate list of fourteen databases specific to each of the two disciplines (see Table 1 for details of the databases listed under appropriate category labels). The lists of databases selected were based on a review of those included in related studies (Cole, 1992; Majid and Tan, 2002; Reed \& Baxter, 1994) and the availability of various databases in education and engineering at HKU. The questionnaire asked the students to rate the level of importance of the databases on a scale of 1 to 5 (with 1 being 'not important', 5 being 'very important', and 0 as 'don't know' [never used or heard of it before]). To see the change in students' perceptions of the importance of the databases over time, they were given the questionnaire three times, at meetings one, three, and five respectively, with meetings separated at intervals of about two and a half months. To clarify the rationale for the students' ratings on some of their responses, a 30-minute interview with each student was conducted at meeting six. The interviews were audio-taped and transcribed for data analysis.

[Insert Table 1a / Table 1b about here]

\section{Key Findings}

\subsection{Ranking of databases by education and engineering students}

To find the relative importance of various databases as perceived by the six education students and the six engineering students, the average ranking of the importance of the databases at meeting five are calculated and presented in descending rank order as rated by the education and engineering students in Table $2 \mathrm{a}$ and Table $2 \mathrm{~b}$ below respectively. Students in both groups have become more familiar with most of the databases during the course of the five meetings (See Table $4 \mathrm{a}$ and Table $4 \mathrm{~b}$ ). When they become more familiar with the databases, they rated the databases significantly higher or lower in meeting 5 than that of meeting 1 (See Table $5 a$ and Table $5 b$ ). This 
suggests that their ratings at meeting 5 were more representative of researchers in their respective disciplines because they now know the databases more and are in a better position to rate the importance of various databases.

[Insert Table 2a / Table 2b around here]

Overall, both groups of students found library catalogs and journal databases most important. The two groups also found the theses database "Dissertation Abstracts Online" important ${ }^{1}$. The other types of databases (journal ranking, news, patents, technical reports and standards) were supplementary to them. Across database categories, the biggest difference between the two groups of students was their ratings on the journal ranking database "Journal Citation Reports.” Within each category, significant differences were also noted. Several databases among the nine common databases for the two groups were rated differently by the students.

Similar to previous research (Bar-Ilan, Peritz \& Wolman, 2003; Clark \& Gomez, 1990; Talja \& Maula, 2003; Weingart \& Anderson, 2000), Dissertation Abstracts, Academic Search Fulltext Elite (a subset of EBSCOhost), ERIC, ScienceDirect, Web of Science were rated by both the education and engineering students in this research to be within the top ten databases. Medline was rated as very important by the two sports education students. In contrast to Weingart \& Anderson's (2000) finding that Current Contents was ranked as the second most important database by users, this database was rated only as the eleventh and the sixteenth by engineering and education students in this research respectively.

\subsection{Examining the perceived importance of various databases}

To illustrate the role and importance of various databases, this section will include excerpts from interviews with students regarding their opinions on the databases.

\subsubsection{Library catalogs}

Both groups of students ranked the three library catalogs listed (the HKU library catalog, other local library catalogs and library catalogs around the world) as within the first seven most important databases, scoring a mean importance of between 3.5 to 4.7 points on a 5-point scale. Among the three library catalogs (and also across all twenty-three databases), the institutional library catalog (HKU library catalog) was ranked as most important. Perhaps it is because the

\footnotetext{
1 To facilitate the discussion, students' ratings are defined as follows: 1 is 'not important', 2 is 'a bit important', 3 is 'fairly important', 4 is 'important' and 5 is 'very important'. For example, education students' ratings on Dissertation Abstracts Online was 3.7 and it would be rounded off to 4 and so it becomes 'important'.
} 
institutional library catalog is usually the first access point for students in their search for academic information. As education student $\mathrm{ZJ}^{2}$ (ratings $\left.4,5,5\right)^{3}$ put it:

I use HKU library catalog most often because it is the central point of information for HKU students. I can use it to check for books available at HKU library. I can access many journals full-text via the HKU library catalog too.

When searching library catalogs around the world, students mainly used the WorldCat since it provides access to thousands of library catalogs worldwide. Compared to the education students, engineering students gave a higher rating for library catalogs around the world while a lower one for the other local library catalogs. A T-test shows that the difference between the two groups of students in their ratings on library catalogs around the world was statistically significant $(p=0.05)$. Why were local library catalogs more important for education students and library catalogs around the world more important to engineering students?

Several of the education students' research projects were related to the local situation and so they gave a high priority to local information. All of the six engineering students' research problems were independent of any social context and none of them perceived local information as particularly important. Probably this difference between the two groups of students explains their different ratings for the two kinds of library catalogs. Education student CK (ratings 4, 3, 4) said:

One thing that I found particularly useful from other local library catalogs was that they contained some irregular local reports that were important to my research. I think most overseas library catalogs would not cover local reports like these.

\subsubsection{Journal databases}

Of the twenty-three databases presented to students in each discipline, 16 and 15 of the education and engineering databases respectively belonged to the journal databases category. The perceived importance differed greatly across the databases within this category. Education students rated only three (Academic Search Fulltext Elite, ERIC and ProQuest) as important and six as unimportant. Engineering students rated five (IEEE Xplore, Engineering Village, ScienceDirect, Web of Science and Springer-LINK) as important and five as not important.

\footnotetext{
2 TZ - To protect the privacy of the participants' information, all students' names have been coded in a way that they cannot be identified.

3 "Ratings 4, 5, 5" refers to the ratings for a database in the first, third, and fifth meetings respectively.
} 


\section{Discipline specific databases versus general databases}

The databases for both education and engineering students can be classified into two types: general (or multi-discipline) and specialized. Among the several journal databases that education/engineering students rated as important, most of them were discipline specific databases. For example, ERIC for education and Engineering Village for engineering. These were also the ones ranked at the top of the journal database category by the students respectively. For both student groups, only one of the journal databases common to both disciplines was regarded as important (ProQuest for education and Web of Science for engineering). Furthermore, these two databases were regarded as least important among the important journal databases.

Two of the six education students were physical education students and for these students, the most specific and important databases were Sportdisc and Medline. These two students gave the highest rating (five points) for these two databases at all three meetings. As the most authoritative sport science database, Sportdisc was no doubt the best database for these two students. Medline was also very useful to them because it covers lots of sources related to health and sports. To these two students' research, ERIC became a general database and so it was less important to these students.

For the two environmental engineering students, the two most important journal databases were Web of Science and ScienceDirect. These two databases cover more Science sources than engineering. The two students found them most useful because their research on "anerobic bacteria" and "hydrogen production from wastewater" were related more to Science than engineering. No wonder the two students would give the highest score for both databases at all three meetings. To these two students, general engineering databases such as Engineering Village became supplementary.

Similar to findings from Murphy, Reinsch, Najm, Dickerson, Seffinger, Adams \& Mishra’s (2003) study, this research shows that students found databases that specialized in their disciplines most useful. Yet, general databases were also useful as supplementary information. As the electrical engineering student PW (ratings on IEEE Xplore - 5, 5, 5) commented:

IEEE Xplore is the most important database for my research because it covers sources that are most relevant to my research. I found most of the things I needed there. Other databases like Inspec provide additional sources too.

\section{Quality of journals covered}

Some databases try to be comprehensive and include all kinds of journals (academic and trade) and other publications in the disciplines that they cover, e.g., ERIC for publications related 
to education. This is both good and bad for the research students. It is good because students will probably not miss anything by searching this kind of database. It is bad because they need to "find the gems among the pebbles."

Other databases focus only on high quality academic journals and this proves to be an important feature for research students. The goal of research studies is to train students to become competent researchers, able to produce high quality academic output. It is thus understandable that databases like Web of Science (which only covers core journals in various disciplines including environmental engineering) and ScienceDirect (which only includes journals by the premier science publisher Elsevier) were rated so highly by the two environmental engineering students.

Academic Search Fulltext Elite captures the best of both worlds. On the one hand, it provides a comprehensive coverage in social science sources including education materials. On the other hand, it enables students to limit their search to peer-reviewed titles only. Searching this way will eliminate sources (e.g., newspapers) that students may not want to see.

\section{Full-text accessibility to the sources covered}

Another important factor for a database to be useful is the full-text accessibility of the sources through the database. As the environmental engineering student TZ commented:

I use ScienceDirect the most because it contains high quality journals in my field. Besides, it has much information available full-text. Therefore, I can access information I need very conveniently from the database.

Two (Academic Search Fulltext Elite and ProQuest) out of three databases rated as important by the education students contain full-text for many of the sources they cover. Similarly, four (IEEE Xplore, ScienceDirect, Web of Science and Springer-LINK) out of the five databases rated as important by the engineering students contain full-text (or links to full-text) for many or all of the sources they cover. Providing full-text to sources is an important database feature for students.

\section{Value-added features of journal databases}

Value-added features such as listing search results by citation frequency are useful. Articles that were cited heavily by others usually represent articles that are of great interest to many researchers. Web of Science enables users to find these heavily cited articles on a topic by ranking the articles using the function “Times Cited.” Education student LM (ratings 0, 5, 5) said:

Web of Science is most useful because it can help me find articles that have been cited by many other people. I found most of my articles there. It is very convenient. 


\subsubsection{Theses databases}

In terms of database category, theses databases (e.g., Dissertation Abstracts Online) were ranked third by both groups of students. Among the twenty-three databases in the two disciplines, Dissertation Abstracts Online was rated as the fifth and sixth most important database by the education and engineering students respectively. The two groups gave a very close average rating score for this database. Engineering student YH (ratings 0, 5, 5) commented on the usefulness of this database:

I found abstracts of theses from it and these theses are very important to my research. I can usually find the full-text of the theses I want from the Web.

\subsubsection{Journal ranking databases}

The major journal ranking database is Journal Citation Report which is useful for students to decide what journals to send their publications to. All six engineering students published one or more journal articles during their graduate study, while none of the education students published any journal articles during the research period. Generally speaking, engineering students are expected to publish at various stages of their research, while there is no such requirement for education students at HKU. This is perhaps why the engineering students rated this database (average rating of 3.06) much higher than the education students (average rating of 1.67). A T-test shows that the difference between the two groups of students was statistically significant $(p<0.05)$. Student YH (ratings $0,1,4)$ said.

I use it to check and see what journals are more credible. There are two reasons for using it. One is for checking core journals for submitting papers. Another is to locate core journals in my field and then I can focus my reading on these important journals.

\subsubsection{News databases}

Overall, the six education students found LexisNexis Academic a bit useful and World News Connection not useful. One education student found LexisNexis Academic important and World News Connection fairly useful because her research topic was media education. She found some topics (e.g., freedom of speech) in news sources useful.

\subsubsection{Patents, technical/research reports and standards databases}

Students were asked to rate IBM patent server, NTIS, and Worldwide Standards Service. The engineering students found patents databases a bit useful and technical reports and standards databases not important. 


\subsection{Changes in students' familiarity with and their perceived importance of databases over time}

This section will first examine the changes in students' familiarity with databases over time. It will then investigate how the changes in students' familiarity with databases affect the perceived importance of the databases and how such changes contribute to the development of their information search expertise.

\subsubsection{Students were unfamiliar with many databases useful to them}

Before joining this research, both the education and engineering students were not familiar with many databases important to them. Table 3a/3b shows the number of education/engineering students who were unfamiliar with databases that were useful to them. Column two lists the databases (from most important to least important) rated as fairly important or above by the students at meeting five. Column three lists the number of students who rated their level of familiarity with the database as unfamiliar (chose " 0 ” or “ 1 ”) at meeting one.

\section{[Insert Table 3a / Table 3b about here]}

Except for the HKU library catalog, which none of the education students were unfamiliar with, all other useful databases were unfamiliar to one or more students at meeting one. Seventyseven percent (sixteen out of twenty-four) of these useful databases on the two lists were not familiar to at least half of the students. Electrical engineering student JC said:

Before I joined this research, I don't know where to look for information except for the Web.

\subsubsection{Students' familiarity with databases increased over time}

To find out whether education/engineering students have become more familiar with various databases over time, Table 4a/4b compares education/engineering students' familiarity rating scores by subtracting their average meeting one score by their average meeting five score for each database. The ones marked with a * are those that were rated as fairly important at meeting five by the students.

[Insert Table 4a/4b about here]

Except for Journal Citation Report and World News Connection that education students' familiarity rating decreased over time, all other databases for both groups were rated with an increase in students' familiarity. The change in students' ratings on their familiarity with the databases was rather significant for quite a number of databases. For the eleven databases that education students rated as fairly important at meeting five (see Table 3), seven had an increase of 
one point or more between meeting one and five in terms of students' familiarity. For engineering students, this occurred with twelve databases out of thirteen. The change in students' familiarity with well-established databases (e.g., ERIC) was much less than databases that were new to the field (e.g., ScienceDirect). Why were these new and yet important databases unknown to so many students, though these databases were listed on the HKU library database list? Information overload appeared to be the reason. As electrical engineering student JC said:

I never realized there was an IBM patent server database though it is on the HKU library database list. There are too many things on the list and so the database did not catch my attention.

\section{Familiarity with databases and the development in information search expertise}

The increase in students' familiarity with databases important to their research contributed greatly to the development of their information search expertise. The following two quotes show that an increase in familiarity with important databases enabled students to be more effective in their information search. In other words, they have grown in their level of information search expertise.

Education student CD: Before joining this research, I was not familiar with databases. Database search was stressful to me and I would usually search like a "blind fly." It was usually the library database system that led me. If I was lucky, I would find something useful. If I was unlucky, then I would find nothing. Now, when I search, I have the knowledge to select databases that are relevant to my research. So it is me who decide what and how to search. Instead of searching aimlessly, I now can search with a direction.

Education student ZJ: Because of my familiarity with many more databases than before, I now know how to access much more information than in the past. This has helped me to be more comprehensive in my information search. So it has provided much contribution to my research.

\subsubsection{Students' perceived importance of databases changed over time}

As students became familiar with various databases, did their perceived importance of the databases change over time? To answer this question, Table $5 \mathrm{a} / 5 \mathrm{~b}$ below compares education/engineering students' rating scores on the perceived importance of the databases by subtracting their average meeting one score from their average meeting five score for each database.

[Insert Table 5a/5b about here]

When compared to meeting one, education students rated eleven databases more important and seven databases less important to them at meeting five. To engineering students, thirteen databases became more important and eight became less important over time. Why did some 
databases become more or less important to students over time? The discussion below presents four factors that were identified to have caused the change in students' ratings.

\section{Change in knowledge of the database}

Earlier discussion pointed out that many students were not familiar with many databases useful to them. When students gained knowledge of these databases, the ratings on their perceived importance would increase accordingly. For example, five of the six education students were originally unfamiliar with Dialog@Carl. These students became familiar with this database, and all of them found it useful. As education student ZJ (ratings 0, 4, 4) put it in meeting six - a brief follow-up interview:

I did not know Dialog@Carl in the beginning. But now I use it quite a lot. It is very useful to me. I would rate it as 5 now.

\section{Change in learning needs}

Sometimes, students' ratings on a database change over time due to a change in their learning needs. For example, when compared to meeting one, five students gave a lower rating for Dissertation Abstract Online in later meetings. It was probably because these beginning research students had little idea about what theses were like and so they wanted to sample some of them by searching the database. Besides, they wanted to see if there were relevant theses for their topics. Once they had seen a number of theses, their need to search for more theses decreased. As education student BW (ratings 4, 4, 2) commented:

Dissertation Abstract Online was important in the beginning because I wanted to read some theses in the area of my research. I did find some useful theses from it. I bought one and borrowed another one via inter-library loan. At that time, I found the database very important, but now I find it not so important. Some journal databases like Academic Search Fulltext Elite are more important now.

\section{Change in research focus}

Some students would change their focus in the process of their research. As a result, their ratings on their perceived importance of various databases also changed. As environmental engineering student TZ put it:

In the beginning, I did something related to the environment and so the Environment Abstracts (TZ's ratings - 5, 2, 2) and Pollution Abstracts (TZ's ratings - 5, 3, 2) were important to me at that time. But now, I am using some new methods to do environmental research. And so I now search for information related to research methods from other databases rather than information about the environment. Therefore, I seldom use the databases on pollution and environment now. 


\section{Found better alternatives}

Some students stopped using some databases that they found useful in the past because they found better alternatives. As a result, their ratings on these databases decreased. As education student CK (ratings 5, 4, 4) explained:

I used Expand Academic ASAP quite a bit initially. It contained full-text journals that others did not have. Later on, I found that many other databases also have full-text and so its importance decreases. In fact, I don't use it now.

\subsubsection{Correlation between students' familiarity with databases and the perceived importance of databases}

The above discussion suggests that when students became familiar with a database, they tended to rate it as being more important to them. Was it by chance that students would rate the databases more important when they became more familiar with them? To answer this question, a correlation test between students' familiarity with databases and the perceived importance of the databases was carried out for each of the databases discussed earlier. The level of statistical significance of the correlation was also checked for each of the databases. Except for a few databases, all have shown a moderate to very high correlation. And the correlation for all these databases was significant. This is similar to Chu's (1997) finding that students' attitudes toward a database will change with the increase of the students' familiarity with the database, but in contradiction to Yuan's (1997) finding that participants' attitudes towards a database did not change greatly with an increase in search experience.

The databases that did not show a strong correlation between students' familiarity and the perceived importance of the database were mostly well-known databases - for example, the HKU library catalog and ERIC. Since students had substantial prior knowledge of these databases, the subsequent change in their familiarity with (and the perceived importance of) the databases can be expected to be low. Hence, the correlation between students' familiarity with these databases and the perceived importance of the databases was low. Some other databases that also did not have a strong correlation between the two were the ones that were clearly irrelevant to students. For example, Mechanical Engineering Abstracts was surely irrelevant to the four electrical engineering students and the two environmental engineering students’ research.

\section{$5 \quad$ Discussion}

\subsection{Improving library support}

Earlier discussion has mentioned that many HKU students had poor knowledge of many databases that were important to them and this seems to be a common phenomenon in many other 
libraries as well (Morner, 1993; Weingart \& Anderson, 2000). As suggested by Weingart \& Anderson (2000), more promotion on the databases and training for students are needed.

\subsubsection{Tailor-made periodic email newsletters for each faculty}

An education student indicated that she did not know about the new and useful full-text education database - E*subscribe. She was very grateful when this study's researcher introduced the database to her. Why did she not know about this wonderful database? Was it because she was not informed about it or was it because she received too much information from the library and so missed out on this important piece of information? To be effective, library promotional efforts should be tailor-made to the specific audience. A general library newsletter may not catch the attention of the various specific student groups. A more tailor-made newsletter (e.g., on a faculty basis) will attract more attention. To engineering students, a general library newsletter that introduces the education $E^{*}$ subscribe database is of no interest to them. Education students who receive a general library newsletter that talks about the usefulness of IEEE Xplore database will also find it a waste of their time. Tailor-made newsletters should perhaps be sent out electronically by email so that the targeted user groups can be reached efficiently and effectively.

\subsubsection{Instruction classes on databases}

Besides tailor-made email newsletters, libraries could offer training classes to research students on a departmental or program basis. Like general newsletters, general instruction classes are not very useful to students as different groups of students have different information needs. Besides introducing the core databases to various groups of students, it is important for librarians to remind students that they might also find other databases important depending on the nature of their research. This is especially true for those engaging in multi-disciplinary research.

\subsubsection{Online subject guides}

Bar-Ilan, Peritz, \& Wolman (2003) found that some self-learners do not like to attend a class, but want to learn on their own. This is also true for some of the students in this study. Some may want to come to a library class, but the class does not fit their schedules. This happens a lot to part-time students. To meet the different learning styles or needs of users, libraries may want to create online subject guides by department or by subject discipline.

\subsection{Improving database design}

Based on the data collected from direct observations, the think aloud protocol, and the interviews, this research identified a number of design aspects that databases could improve on so that they would be more useful to students. The first three points below apply to all kinds of databases, while the last two points are specifically for library catalogs. 


\subsubsection{Databases should use informative names rather than obscure names}

The name of a database should describe the content of the database. This will help users to decide if the database is suitable or not. The name "Web of Science" carries the connotation that it is about Science. Because of that, several education students did not even try the database since they thought it was irrelevant to their discipline. Once these students tried the database, they found some use for it. One even found it to be the best database for her research. As an interim solution to this problem, libraries may want to add scope notes for the coverage of databases on the selection screens/menus.

\subsubsection{Database vendors should make their databases available full-text}

Designers of non-full-text databases should make the sources in their databases available in full-text so as to make them more useful to their users. Otherwise, they could be phased out of the market as fewer and fewer people will use them. Dialog@Carl is one such example. This database contains about 400 databases and it was the most important online database in the 1970's and the 1980's. However, the database continued to provide index and abstracts only for the journal articles that it covered even in the 1990's. Even now, Dialog@Carl does not provide full-text for its journal databases. At the same time, its old and new competitors have started to offer full-text databases. Gradually, Dialog@Carl changed from being the most popular to a marginal database. This situation also happened to other non-full-text databases.

\subsubsection{Databases should improve their levels of usability by conducting usability studies}

Many databases were found to have usability problems.

\section{Misleading interface design}

At the time this research was conducted, Web of Science displayed "Page 1 (Articles 1 -10)" at the top of the search results page. This has led many students to think that the search found ten records only. In fact, the search found many more records, but the number of records found were displayed at the end of the page rather than at the beginning of the page. Student JC encountered this problem when using the database. He said:

Why couldn’t I see how many records I found?

The students in general expected to see the total number of records found at the top rather than at the bottom of the search results page. Ahmed et al. (2004) also identified this problem in database designs. Perhaps due to Ahmed or some other similar studies on the database, Web of Science has already rectified this problem in a recent update. 


\section{Confusing messages}

Education student LA found some books he wanted from the library catalog of the Chinese University of Hong Kong. The status of these books was "not check out" and LA interpreted it as "cannot be checked out." The message actually means the item has not been checked out. Perhaps changing the message to "available" will solve the problem.

\subsubsection{Library catalogs should provide a description of what they contain}

Many library catalogs including HKU's do not provide a description of what they contain. Many librarians think that every student should know what their library catalogs contain. In fact, many students do not know, and as a result, students are not able to search the library catalogs effectively. For example, education student BW asked at the fourth meeting:

Can I find journal articles from the HKU library catalog?

Although he has been using the HKU library catalog for about one year, he still did not have a clear idea of what the library catalog contained.

\subsubsection{Library catalogs should include table of contents for all records}

In the HKU library catalog, most of the newer records contain a table of contents for the items. Quite a few students found such information very useful. When asked about the importance of these tables of contents, engineering student YH said:

The table of contents in a library catalog is like the abstract of articles in a journal database. Comparing the importance of different parts in a library catalog record, the table of contents would be worth 50 points out of 100 points in a record. The title is worth 30 to 40 points, the author, and other information worth 10 to 20 points.

Catalogers spend much time and effort on choosing appropriate subject headings for items to be recorded in a library catalog. However, students' perceived importance for such information is rather low. On the contrary, students put great value on the table of contents which is not included in standard cataloging practice. Twenty or thirty years ago, it was understandable why computerized library catalog records did not include tables of contents, since the hard disk cost in those days was high. Nowadays, it makes almost no difference to include a table of contents in a library catalog record in terms of hard disk cost. Cataloging practice should catch up with this important and yet easily met users’ need.

\section{Conclusion}

This article examined the importance of various types of databases to education and engineering students. Both groups of students found library catalogs and journal databases most 
important, and found the theses database "Dissertation Abstracts Online" important. Three criteria were identified for a journal database to be useful: (1) it covers the specific subject discipline(s) that is/are relevant to the students' research; (2) the database contains entries from high quality academic journals; and (3) it has full-text (or links to full-text) for the sources that it covers.

Among the databases that students rated as fairly important or above at meeting five, seventy-seven percent (sixteen out of twenty-four) of these useful databases were unknown to half (or more) of the students initially. This implies that much work needs to be done to inform and instruct students about these "treasures." Over the entire research period, students changed dramatically in both their familiarity with databases and in the perceived importance of the databases. Overall, it was found that when students became familiar with the databases, they also found the databases more important to their research. Four factors were identified for the causes of these changes in students' ratings: lack of knowledge of the database, change in learning needs, change in research focus, and finding better alternatives. This article also shows that an increase in students' familiarity with databases will contribute to the development of their information search expertise.

On the basis of observations made of students' search activities using databases, this article made suggestions on ways to improve library support and database design. To meet the specific needs of specific student groups, the library may want to inform its various target user groups by sending out periodic email newsletters; it can instruct its users via tailor-made classes or online subject guides. To better meet the needs of the users, databases should: (1) use informative names and provide scope descriptions for the databases, (2) provide full-text of the sources covered, and (3) improve the databases' usability by conducting usability studies. Lastly, library catalogs should provide a description of what they contain and provide tables of contents for all their records.

\section{Limitations and Further Studies}

This study adopted an in-depth longitudinal approach to study twelve students. Although it reveals various interesting observations and findings, it lacks the power of generalization due to its small sample size. Based on the results of this study, it would be meaningful to carry out further studies with a bigger sample to see if the findings identified in this study will still hold true.

\section{References}

Ahmed, S. M. Z., McKnight, C. \& Oppenheim, C. (2004). A study of users' performance and satisfaction with the Web of Science IR interface. Journal of Information Science, 30(5), 459-468.

Bar-Ilan, J., Peritz, B. C., \& Wolman, Y. (2003). A survey on the use of electronic databases and electronic journals accessed through the web by the academic staff of Israeli universities.

The Journal of Academic Librarianship, 29(6), 346-361. 
Barry, C.A. (1997). Information skills for an electronic world: Training doctoral research students. Journal of Information Science, 23(3), 225-238.

Bates, M.J. (1977). Factors affecting subject catalog search success. Journal of the American Society for Information Science, 28(3), 161-169.

Campbell, R.L., Brown, N.R., \& DiBello, L.A. (1992). The programmer's burden: developing expertise in programming. In R.R. Hoffman (Ed.), The psychology of expertise: Cognitive research and empirical AI. New York: Springer-Verlag New York, Inc.

Campbell, R.L. \& Dibello, L. (1996). Studying human expertise - beyond the binary paradigm. Journal of Experimental \& Theoretical Artificial Intelligence, 8(3-4), 277-291.

Chase, W.G., \& Simon, H.A. (1973). Perception in chess. Cognitive Psychology, 4, 55-81.

Chi, M.T.H., Glaser, R., \& Farr, M.J. (Eds.) (1988). The nature of expertise. New Jersey: Lawrence Erlbaum Associates.

Chu, S. (1995). Difficulties that may be encountered by students in searching the Dow Jones News/Retrieval database and the UMI Proquest full-image databases. Proceedings of the International Online Information Meeting, London, UK, 19, 81-100.

Chu, S. (1997). Extel: An International Stock Database for Academic Libraries? Proceedings of the International Online Information Meeting, London, UK, 21, 119-137.

Clark, K.E. \& Gomez, J. (1990). Faculty Use of Databases at Texas A\&M University. RQ, 30(2), 241248.

Cole, K. (1992). Doctoral students in Education and factors related to the literature review process. Unpublished master thesis, Fort Hays State University.

Compton, M.L. (1989). A study of the information resources and library services used by doctoral students in science education at the University of Georgia. Unpublished master thesis, University of Georgia.

De Groot, A.D. (1965). Thought and choice in chess. The Hague, Netherlands: Mouton.

De Groot, A.D. (1966). Perception and memory versus thought: Some old ideas and recent findings. In B. Kleinmuntz (Ed.), Problem solving (pp. 19-50). New York: Wiley.

Drabenstott, K.M., \& Weller, M.S. (1996). Failure analysis of subject searches in a test of a new design for subject access to online catalogs. Journal of the American Society for Information Science, 47(7), 519-537.

Dreyfus, S.E., \& Dreyfus, H.L. (1980). A five-stage model of the mental activities involved in directed skill acquisition. Unpublished report supported by the Air Force Office of Scientific Research. United States Air Force. (Contract F49620-79-C-0063), University of California at Berkeley.

Dreyfus, H.L., \& Dreyfus, S.E. (1986) Mind over machine. New York: Free Press.

Hildreth, C.R. (1997). The use and understanding of keyword searching in a university online catalog. Information Technology and Libraries, 16(2), 52-62. 
Hsieh-Yee, I. (1993). Effects on search experience and subject knowledge on the search tactics of novice and experienced searchers. Journal of the American Society for Information Science, 44(3), 161-174.

Keller, M. (2002). eJUSt, Follow-up Survey Highlights. Retrieve Feb. 13, 2005, from the Stanford University Libraries Web site: http://ejust.stanford.edu/findings3/3SurveyHighlights.html

Kroerke, D.M. (1995). Database processing: Fundamentals, design, and implementation. Englewood Cliffs, N.J.: Prentice Hall.

Kuhlthau, C.C. (1999). The role of experience in the information search process of an early career information worker: Perceptions of uncertainty, complexity, construction, and sources. Journal of the American Society for Information Science. 50(5), 399-412.

Larkin, J.H., McDermott, J., Simon, D.P., \& Simon, H.A. (1980). Expert and novice performance in solving physics problems. Science, 208, 1335-1342.

Lazonder, A.W., Biemans, H.J.A., \& Wopereis, I.G.J.H. (2000). Differences between novice and experienced users in searching information on the World Wide Web. Journal of the American Society for Information Science, 51(6): 576-581.

Libutti, P., \& Kopala, M. (1995). The doctoral student, the dissertation, and the library: A review of the literature. Reference Librarian, No. 48, 5-25.

Majid, S. and Tan, A.T. (2002). Usage of information resources by computer engineering students: a case study of Nanyang Technological University, Singapore. Online Information Review, 26(5), 318325.

Marchionini, G., Dwiggins, S., Katz, A., \& Lin, X. (1993). Information seeking in full-text end-useroriented search systems: The roles of domain and search expertise. Library \& Information Science Research, 15, 35-69.

Marchionini, G., Meadow, C., Dwiggins, S., Lin, X., Wang, J., \& Yuan, W. (1991). A study of user interaction with information retrieval interfaces: Progress report. Canadian Journal of Information Science, 16(4), 42-59.

Morner, C.J. (1993). An instrument for measuring library skills of Education graduate students. Unpublished doctoral dissertation, Boston College, Boston.

Murphy, L.S., Reinsch, S., Najm, W.I., Dickerson, V.M., Seffinger, M.A., Adams A., \& Mishra, S.I. (2003). Spinal palpation: the challenges of information retrieval using available databases. Journal of Manipulative and Physiological Therapeutics, 26(6): 374-382.

Palmquist, R.A. \& Kim, K.S. (2000). Cognitive style and on-line database search experience as predictors of web search performance. Journal of the American Society for Information Science, 51(6): 558-566.

Reed, J.G., \& Baxter, P.M. (1994). Using reference databases. In H. Cooper \& L.V. Hedges (Eds.), The handbook of research synthesis (pp. 57-66). New York: Russell Sage Foundation.

Rogers, S. A. (2001). Electronic Journal Usage at Ohio State University. College \& Research Libraries, 62, 25-34. 
Simon, C.E. (1995). Information retrieval techniques: The differences in cognitive strategies and search behaviors among graduate students in an academic library. Unpublished doctoral dissertation, Wayne State University, Michigan.

Talja, S. \& Maula, H. (2003). Reasons for the Use and Non-use of Electronic Journals and Databases. Journal of Documentation, 59(6), 673-691.

Tefera, T. \& Wood, F, \& Ford, N. (1999). CD-ROM services in Ethiopia: a survey. Journal of Information Science, 25(4), 327-333.

Tillotson, J. (1995). Is keyword searching the answer? College and Research Libraries, 56(3), 199206.

Walton, R.E., Adams, M.L., Glodsmith, L.T., \& Feldman, D.H. (1988). Affect and development in a nonuniversal domain. Paper presented at the Jean Piaget Society meeting, Philadelphia.

Weingart, S. J. \& Anderson, J. A. (2000). When Questions are Answers: Using a Survey to Achieve Faculty Awareness of the Library's Electronic Resources". College \& Research Libraries, 61, 127134.

Wiedenbeck, S., \& Scholtz, J. (1996). Adaptation of programming plans in transfer between programming languages: A developmental approach. In W.D. Gray \& D.A. Boehm-Davis (Eds.), Empirical studies of programmers: Sixth workshop (pp. 233-253). Norwood, NJ: Ablex.

Yuan, W. (1995). Longitudinal study of end-user searching behavior of law students in information retrieval. Unpublished doctoral dissertation, University of Toronto, Ontario.

Yuan, W. (1997). End-User Searching Behavior in Information Retrieval: A Longitudinal Study. Journal of the American Society for Information Science, 48(3), 218-234.

Zaporozhetz, L.E. (1987). The Dissertation Literature Review: How Faculty Advisors Prepare Their Doctoral Candidates. Unpublished doctoral dissertation, University of Oregon, Oregon. 
Table 1 . The databases ${ }^{4}$ listed in the survey questionnaires distributed to education and engineering students respectively:

Table 1a

Categories of Databases Included in the Questionnaire for Education Students

Library catalogs

HKU Library Catalog

Other local library catalogs

Library catalogs around the world

\section{Journal articles}

Academic Search Fulltext Elite

Applied Social Science Index

Australian Education Index

Current Contents Connect

Dialog@Carl

Emerald Intelligence and Fulltext

ERIC

Expand Academic ASAP

Inside Social Science and Humanities

International ERIC

Periodicals Contents Index

ProQuest

PsycLIT

Social Sciences Index

Sociofile

Web of Science

\section{Theses}

Dissertation Abstracts Online

\section{Journal ranking}

Journal Citation Report

\section{News}

LexisNexis Academic

World News Connection

Table 1b

\begin{tabular}{l}
$\begin{array}{l}\text { Categories of Databases Included in } \\
\text { the Questionnaire for Engineering Students }\end{array}$ \\
\hline Library catalogs \\
HKU Library Catalog \\
Other local library catalogs \\
Library catalogs around the world
\end{tabular}

\section{Journal articles}

Abstracts in New Tech. and Engineering

ASCE Journals on CD-ROM

Compendex

Current Contents Connect
Dialog@Carl
Engineering Village
IEEE Xplore
Inside Science Plus
Inspec
Mechanical Engineering Abstracts
ProQuest
ScienceDirect
Springer-LINK
Water Resources Abstracts
Web of Science

Theses

Dissertation Abstracts Online

\section{Journal ranking \\ Journal Citation Report}

\section{Patents}

Patents databases

Standards

Worldwide Standards

Technical/Research reports

NTIS

*Note: The shaded databases are the nine common ones to both disciplines. The other fourteen are more specific to either of the two disciplines. This applies to other tables in this article too.

\footnotetext{
${ }^{4}$ This article took a broad definition for database - a large collection of files and records managed by a database management system (Kroerke, 1995).
} 
Table 2a

Ranking of Databases by Education Students: (Students’ Average Ratings at Meeting Five)

\begin{tabular}{cll}
\hline Rank & \multicolumn{2}{c}{ Average score for each database } \\
\hline 1 & HKU Library Catalog & 4.7 \\
2 & Academic Search Fulltext Elite & 4.5 \\
3 & ERIC & 4.3 \\
4 & Other local library catalogs & 4.0 \\
5 & Dissertation Abstracts Online & 3.7 \\
6 & ProQuest & 3.7 \\
7 & Library catalogs around the world & 3.5 \\
8 & Dialog@Carl & 3.3 \\
9 & International ERIC & 3.0 \\
10 & Web of Science & 2.8 \\
11 & Applied Social Science Index & 2.7 \\
12 & LexisNexis Academic & 2.3 \\
13 & Periodicals Contents Index & 2.0 \\
14 & Journal Citation Report & 1.8 \\
15 & Expand Academic ASAP & 1.8 \\
16 & Current Contents Connect & 1.7 \\
17 & Australian Education Index & 1.3 \\
18 & PsycLIT & 1.3 \\
19 & Social Sciences Index & 1.3 \\
20 & Inside Social Science \& Humanities & 1.2 \\
21 & World News Connection & 1.2 \\
22 & Sociofile & 1.0 \\
23 & Emerald Intelligence and Fulltext & 1.0 \\
\hline & &
\end{tabular}

Table 3a

Number of Education Students Who Were Not

Familiar with Databases That Were Useful to Them

\begin{tabular}{clc}
\hline Rank & $\begin{array}{l}\text { Education students: } \\
\text { databases rated as } \\
\text { fairly important or above }\end{array}$ & $\begin{array}{c}\text { No. of students } \\
\text { unfamiliar with } \\
\text { the database }\end{array}$ \\
\hline 1 & HKU Library Catalog & 0 \\
2 & Academic Search Fulltext Elite & 3 \\
3 & ERIC & 1 \\
4 & Other local library catalogs & 3 \\
5 & Dissertation Abstracts Online & 2 \\
6 & ProQuest & 3 \\
7 & Lib catalogs around the world & 5 \\
8 & Dialog@Carl & 5 \\
9 & International ERIC & 4 \\
10 & Web of Science & 3 \\
11 & Applied Social Science Index & 5 \\
\hline
\end{tabular}

Table 2b

Ranking of Databases by Engineering Students: (Students' Average Ratings at Meeting Five)

\begin{tabular}{clc}
\hline Rank & \multicolumn{2}{c}{ Average score for each database } \\
\hline 1 & HKU Library Catalog & 4.7 \\
2 & IEEE Xplore & 4.3 \\
3 & Engineering Village & 4.0 \\
4 & ScienceDirect & 4.0 \\
5 & Library catalogs around the world & 4.0 \\
6 & Dissertation Abstracts Online & 3.8 \\
7 & Other local library catalogs & 3.5 \\
8 & Journal Citation Report & 3.5 \\
9 & Web of Science & 3.5 \\
10 & Springer-LINK & 3.5 \\
11 & Current Contents Connect \\
12 & Inspec & 2.8 \\
13 & Compendex & 2.8 \\
14 & Dialog@Carl & 2.7 \\
15 & US Patents database & 2.7 \\
16 & Inside Science Plus & 2.3 \\
17 & ASCE Database & 1.8 \\
18 & Water Resources abstract & 1.3 \\
19 & Worldwide standards & 1.3 \\
20 & ProQuest & 1.2 \\
21 & NTIS & 1.2 \\
22 & Abstracts in New Tech. \& Engineering & 1.0 \\
23 & Mechanical engineering abstracts & 1.0 \\
\hline & &
\end{tabular}

Table 3b

Number of Engineering Students Who Were Not

Familiar with Databases That were Useful to Them

\begin{tabular}{clc}
\hline Rank & $\begin{array}{l}\text { Engineering students: } \\
\text { databases rated as } \\
\text { fairly important or above }\end{array}$ & $\begin{array}{c}\text { No. of students } \\
\text { unfamiliar with } \\
\text { the database }\end{array}$ \\
\hline 1 & HKU Library Catalog & 1 \\
2 & IEEE Xplore & 2 \\
3 & Engineering Village & 2 \\
4 & ScienceDirect & 4 \\
5 & Lib catalogs around the world & 4 \\
6 & Dissertation Abstracts Online & 2 \\
7 & Other local library catalogs & 3 \\
8 & Journal Citation Report & 3 \\
9 & Web of Science & 2 \\
10 & Springer-LINK & 4 \\
11 & Current Contents Connect & 4 \\
12 & Inspec & 3 \\
13 & Compendex & 4 \\
\hline
\end{tabular}


Table 4a

Education Students:

Change in Familiarity with Databases

Meeting 5 Minus Meeting 1 (Average Score)

*Dialog@Carl 2.2

*Library catalogs around the world

1.8

*Academic Search Fulltext Elite

*Applied Social Science Index

1.5

*Other local library catalogs 1.2

*ProQuest

1.2

LexisNexis Academic

1.0

*International ERIC

1.0

Periodicals Contents Index

0.7

*Dissertation Abstracts Online

0.7

*ERIC 0.7

*HKU Library Catalog

0.5

Current Contents Connect

0.5

Expand Academic ASAP

0.3

Australian Education Index

0.2

Inside Social Science and Humanities

0.2

*Web of Science

0.2

Emerald Intelligence and Fulltext

0.0

PsycLIT

0.0

Social Sciences Index

0.0

Sociofile

0.0

Journal Citation Report

$-0.2$

World News Connection
Table 4b

Engineering Students:

Change in Familiarity with Databases

Meeting 5 Minus Meeting 1 (Average Score)

*Springer-LINK 2.5

*Current Contents Connect 2.2

*ScienceDirect 2.2

*Engineering Village $\quad 2.0$

Dialog@Carl 1.8

*Library catalogs around the world $\quad 1.8$

*Compendex $\quad 1.7$

*Journal Citation Report 1.7

Inside Science Plus $\quad 1.3$

*Dissertation Abstracts Online 1.2

*Inspec $\quad 1.2$

*Other local library catalogs $\quad 1.2$

*IEEE Xplore $\quad 1.2$

*HKU Library Catalog $\quad 1.0$

US Patents database $\quad 1.0$

ProQuest $\quad 0.7$

*Web of Science $\quad 0.7$

NTIS 0.5

Worldwide standards $\quad 0.5$

Abstracts in New Tech. and Engineering $\quad 0.3$

ASCE Database $\quad 0.3$

Mechanical engineering abstracts $\quad 0.2$

Water Resources abstract

0.0




\section{Table 5a}

\section{Education Students:}

Change in Perceived Importance of Databases Meeting 5 Minus Meeting 1 (Average Score)

\begin{tabular}{lr}
\hline Dialog@Carl & 2.3 \\
Academic Search Fulltext Elite & 1.5 \\
International ERIC & 1.2 \\
Library catalogs around the world & 1.0 \\
LexisNexis Academic & 1.0 \\
ERIC & 1.0 \\
ProQuest & 0.8 \\
Web of Science & 0.7 \\
Other local library catalogs & 0.5 \\
Current Contents Connect & 0.2 \\
Expand Academic ASAP & 0.2 \\
HKU Library Catalog & 0.0 \\
Emerald Intelligence and Fulltext & 0.0 \\
Inside Social Science and Humanities & 0.0 \\
PsycLIT & 0.0 \\
Sociofile & 0.0 \\
Applied Social Science Index & -0.2 \\
Journal Citation Report & -0.3 \\
World News Connection & -0.3 \\
Periodicals Contents Index & -1.0 \\
Australian Education Index & -1.0 \\
Dissertation Abstracts Online & -1.2 \\
Social Sciences Index & -1.5 \\
\hline
\end{tabular}

Table 5b

Engineering Students:

Change in Perceived Importance of Databases Meeting 5 Minus Meeting 1 (Average Score)

\begin{tabular}{lr}
\hline Springer-LINK & 2.2 \\
ScienceDirect & 2.0 \\
Current Contents Connect & 1.8 \\
Dialog@Carl & 1.7 \\
Compendex & 1.5 \\
Engineering Info Village & 1.3 \\
Journal Citation Report & 0.7 \\
Dissertation Abstracts Online & 0.5 \\
IEEE Xplore & 0.5 \\
Library catalogs around the world & 0.3 \\
Inspec & 0.3 \\
Other local library catalogs & 0.2 \\
Inside Science Plus & 0.2 \\
Web of Science & 0.0 \\
Worldwide standards & 0.0 \\
Mechanical engineering abstracts & -0.2 \\
Water Resources abstract & -0.2 \\
HKU Library Catalog & -0.3 \\
US Patents database & -0.3 \\
NTIS & -0.3 \\
ASCE Database & -0.3 \\
ProQuest & -1.0 \\
Abstracts in New Tech. and Engineering & -1.8 \\
\hline &
\end{tabular}

